\title{
Article \\ Solution Structures of Bacillus anthracis Protective Antigen Proteins Using Small Angle Neutron Scattering and Protective Antigen 63 Ion Channel Formation Kinetics
}

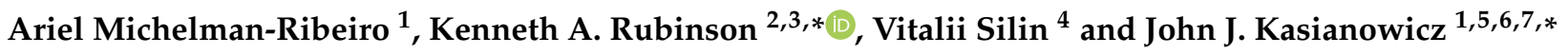 \\ 1 Physical Measurement Laboratory, National Institute of Standards and Technology, \\ Gaithersburg, MD 20899, USA; lasirenita54@yahoo.com \\ 2 NIST Center for Neutron Research, National Institute of Standards and Technology, \\ Gaithersburg, MD 20899, USA \\ 3 Department of Biochemistry and Molecular Biology, Wright State University, Dayton, OH 45435, USA \\ 4 SPR Biosystems, Brunswick, MD 21758, USA; vital@sprbiosystems.com \\ 5 Department of Applied Physics \& Applied Math, Columbia University, New York, NY 10027, USA \\ 6 Freiburg Institute for Advanced Studies, Universität Freiburg, 79104 Freiburg, Germany \\ 7 Department of Physics, University of South Florida, Tampa, FL 33628, USA \\ * Correspondence: Rubinson@wright.edu (K.A.R.); jjkemail@mac.com (J.J.K.)
}

Citation: Michelman-Ribeiro, A.;

Rubinson, K.A.; Silin, V.;

Kasianowicz, J.J. Solution Structures of Bacillus anthracis Protective Antigen Proteins Using Small Angle Neutron Scattering and Protective Antigen 63 Ion Channel Formation Kinetics. Toxins 2021, 13, 888. https:// doi.org/10.3390/toxins 13120888

Received: 5 November 2021 Accepted: 6 December 2021 Published: 11 December 2021

Publisher's Note: MDPI stays neutral with regard to jurisdictional claims in published maps and institutional affiliations.

Copyright: (c) 2021 by the authors. Licensee MDPI, Basel, Switzerland. This article is an open access article distributed under the terms and conditions of the Creative Commons Attribution (CC BY) license (https:/ / creativecommons.org/licenses/by/ $4.0 /)$.

\begin{abstract}
We are studying the structures of bacterial toxins that form ion channels and enable macromolecule transport across membranes. For example, the crystal structure of the Staphylococcus aureus $\alpha$-hemolysin ( $\alpha$-HL) channel in its functional state was confirmed using neutron reflectometry (NR) with the protein reconstituted in membranes tethered to a solid support. This method, which provides sub-nanometer structural information, could also test putative structures of the Bacillus anthracis protective antigen 63 (PA63) channel, locate where B. anthracis lethal factor and edema factor toxins (LF and EF, respectively) bind to it, and determine how certain small molecules can inhibit the interaction of LF and EF with the channel. We report here the solution structures of channel-forming PA63 and its precursor PA83 (which does not form channels) obtained with small angle neutron scattering. At near neutral pH, PA83 is a monomer and PA63 a heptamer. The latter is compared to two cryo-electron microscopy structures. We also show that although the $\alpha$-HL and PA63 channels have similar structural features, unlike $\alpha-\mathrm{HL}$, PA63 channel formation in lipid bilayer membranes ceases within minutes of protein addition, which currently precludes the use of NR for elucidating the interactions between PA63, LF, EF, and potential therapeutic agents.
\end{abstract}

Keywords: A-B toxins; alpha-hemolysin; anthrax; Bacillus anthracis; bacterial toxin; $\beta$-barrel; endotoxin; ion channel; pore forming toxin; PA63; PA83; protective antigen

Key Contribution: Solution structures for the two major forms of Bacillus anthracis protective antigens (PA83 and PA63) were determined using small angle neutron scattering. The result obtained for PA83 at slightly basic $\mathrm{pH}$ is consistent with $\mathrm{x}$-ray crystallographic data. At neutral $\mathrm{pH}$, the PA63 structure is consistent with one of two cryo-electron microscopy structures. In addition, the kinetics of PA63 channel formation in planar lipid bilayers was measured and points to ways that might increase the channel density in membranes, which is a requirement for neutron reflectometry structural studies of B. anthracis A-B toxin interactions.

\section{Introduction}

Ion channels and pore-forming toxins have been studied extensively because of their significance in the proper function and disease states of different tissues [1-3]. One class of channels is of particular interest because the pore-forming toxins work in concert with other proteins that are produced by their respective bacteria. As an example, Bacillus anthracis is unusual in that it secretes two A toxins (lethal factor, LF and edema factor, EF) 
and one B-toxin (protective antigen 83, PA83) [4,5]. The latter binds to the exterior of cell membranes [6], is cleaved by a furin-like protease to PA63 [7], and one of the products (PA63) forms a heptameric pre-pore complex PA637 [8]. LF or EF associates with PA637, and the A-B complexes of $\mathrm{LF}-\mathrm{PA} 63_{7}$ or EF-PA63 7 are removed from the cell membrane exterior by endocytotic vesicles, where PA637 channel formation is thought to occur after endosome acidification [9]. $\mathrm{PA}_{6} 3_{7}$ is required for LF and EF to gain entry into the cytoplasm: LF inhibits mitogen-activated protein kinases (which leads to apoptosis), and EF leads to increased cyclic AMP concentration (which leads to cell edema) [10,11].

Electrophysiology experiments with PA63 channels in planar bilayer membranes demonstrate that at neutral $\mathrm{pH}, \mathrm{LF}$ and $\mathrm{EF}$ bind reversibly to the cap domain of the channel, with a dissociation constant $K_{D} \approx 40 \mathrm{pM}$ (where $\mathrm{M}=\mathrm{mol} \mathrm{L}^{-1}$ ) [12-14]. LF or EF bind to the channel to block the ionic current in a diode-like fashion (blocked for positive but not negative applied potentials) [12]. Similar experiments showed that $N$-terminal fragments of $\mathrm{LF}$ and $\mathrm{EF}\left(\mathrm{LF}_{\mathrm{N}}\right.$ and $\mathrm{EF}_{\mathrm{N}}, \approx 30 \mathrm{~kg} \mathrm{~mol}^{-1}$ each) also bind to the PA63 7 channel $[15,16]$. When the bulk $\mathrm{LF}_{\mathrm{N}}$ and or $\mathrm{EF}_{\mathrm{N}}$ concentration is reduced, under some solution conditions, the channel block by these fragments ceases, which is consistent with a simple reversible binding scheme.

The latter effect has also been interpreted as the unfolding and complete transport of the $\mathrm{LF}_{\mathrm{N}}$ and $\mathrm{EF}_{\mathrm{N}}$ fragments through the PA63 $3_{7}$ channel. By inference, it was suggested that at acidic solution $\mathrm{pH}$ (e.g., $\mathrm{pH} \approx 5.5)$, full-length $\mathrm{LF}\left(90 \mathrm{~kg} \mathrm{~mol}^{-1}\right)$ and $\mathrm{EF}\left(89 \mathrm{~kg} \mathrm{~mol}^{-1}\right)$ would similarly unfold while bound to the channel, completely translocate past the $1.1 \mathrm{~nm}$ diameter narrowest constriction in the pore [17-19], and refold when they emerge as a whole in the cytoplasm. However, experiments that better mimicked the acidification inside endosomes (i.e., pH 5.5 with LF or EF still in the bulk aqueous phase) suggested that LF and EF become irreversibly bound to the PA637 channel cap domain [20], which would inhibit their complete translocation through the pore. This irreversible binding result is consistent with the observation that the complex of LF-PA637 was found in the blood of moribund animals previously subjected to anthrax inhalation [13]. An alternative to the hypothesis of the complete translocation of LF and EF through the PA63 channel was suggested because of the last two experimental results and two other findings: (1) lipid membranes are more likely to rupture at relatively low transmembrane potentials only when either LF or EF became irreversibly bound to the channel [20] and (2) the enzymatic activity of LF alone is only slightly greater than that of the complex of LF-PA63 7 [13]. The latter further suggests that perhaps it is the complex of these two A-B toxins that cause the lethal effects of anthrax infection [13]. However, more research is needed to test these two hypotheses.

Determining the structures of the B. anthracis A-B toxins separately, or bound in the complex, should help understand their mechanisms of action and possibly lead to more effective therapeutic agents against them. There are several methods available for this purpose, including x-ray crystallography [21-24], cryo-electron microscopy (cryo-EM) [25-28], small angle neutron scattering (SANS) [29], and neutron reflectometry (NR) [30].

We demonstrated the feasibility of neutron reflectometry for membrane protein structure determination using Staphylococcus aureus $\alpha$-hemolysin ( $\alpha-\mathrm{HL})$ [31]. At that time, it was known that $\alpha$-HL [32] forms heptameric pores [33], and a crystal structure of the heptamer from solution was determined in 1996 [23] (Figure 1A). However, because the $\alpha$-HL channel has been used in a wide range of single-molecule detection and identification applications [34-44], we wanted to develop a structural method for the molecule in its functional state. To accomplish that, the protein was reconstituted on membranes tethered to a solid support, as had been done by Cornell and colleagues for gramicidin-based sensors [45]. Surface plasmon resonance [46] and electrochemical impedance spectroscopy [31,47] were used to verify that the functional channels had absorbed the tethered membranes. The results demonstrated that the NR structure determination method requires close-packed $\alpha$-HL channels in the membrane [31]. This was made possible because $\alpha$-HL spontaneously 
and continuously forms channels in planar black lipid membranes and tethered membranes without the need for other agents (e.g., detergents).

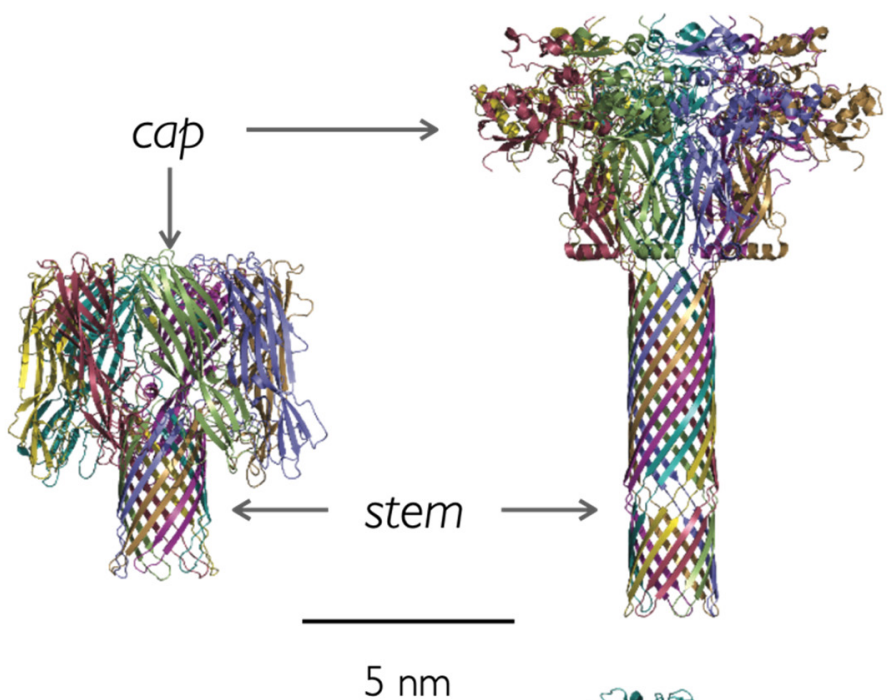

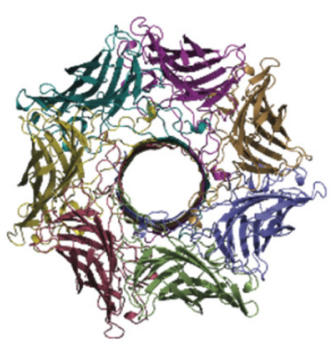

$(\mathrm{a}-\mathrm{HL})_{7}$

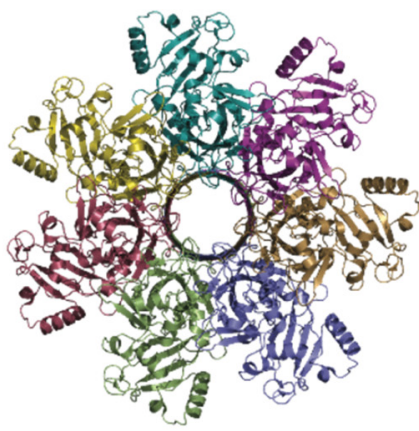

(PA63) 7

A

B

Figure 1. Side and top views of the solution structures of heptameric ion channels formed by the bacterial endotoxins (A) Staphylococcus aureus alpha-hemolysin and (B) activated Bacillus anthracis protective antigen (PA63) from PDB 7AHL [23], and PDB 3J9C [48], respectively. The $\beta$-barrel segment of the $\alpha$-HL channel just spans the lipid bilayer membranes. The upper portions of both structures are referred to as the cap domain. The length of the PA $63_{7} \beta$-barrel stem section, determined with a combination of site-directed mutagenesis and electrophysiology [49] following the method of Akabas and Karlin [50], is over two-fold greater than the membrane thickness. It was assumed that the segment between the cap domain and the membrane-solution interface interacts with receptors on cell surfaces.

We report here the use of SANS to determine the structures of B. anthracis PA83 and PA63 in solution and electrophysiology to investigate the channel-formation kinetics of PA63 in lipid bilayers. Ultimately, the goal is to test the validity of detailed structural models of the $\mathrm{PA}_{7} 3_{7}$ channel model in solution (with an inferred $\beta$-barrel) [48] (Figure 1B) and determine where LF and EF bind to it.

\section{Results}

Neutron scattering can be used to determine the structures of proteins in solution because, as with light, there is contrast between the water molecules and the protein. For light scattering, the contrast is due to a difference in the dielectric constants. With neutrons, the contrast (related to the scattering length density, SLD) is due to the different atom contents in the scatterer (especially the non-exchangeable protons in the protein) and the 
solvent $\mathrm{D}_{2} \mathrm{O}$; there is a marked difference in the scattering amplitudes of neutrons by hydrogen and deuterium [51-53].

In light scattering, the wavelength $(\approx 5000 \AA)$ is much greater than the size of a protein. The interpretation of the results assumes that the protein scatters light as if it were a point source. However, for cold neutrons, such as those used here, their de Broglie wavelength is $5 \AA$ to $6 \AA$. Because the proteins are larger than this wavelength, the scattering provides information about their shapes. As a result, SANS can be used to study the structures of a wide range of materials, including biological macromolecules [52,54,55].

To a first approximation, peaks and shoulders in plots of the scattering intensity $I(q)$ versus the momentum transfer $q$ (e.g., Figure 2) are caused by features in the objects with sizes $\approx 2 \pi / q$. However, the determination of the protein's shape requires mathematical modeling. Here, we used simple geometrical sizes and shapes (spheres, cylinders, parallelepipeds) to approximate the proteins' structures for these calculations. Shapes are assumed to be homogeneous in SLD throughout, and the total SLD is the sum of the different atomic components. In addition, the surrounding water is homogeneous at the wavelength scale but with a different, known SLD.
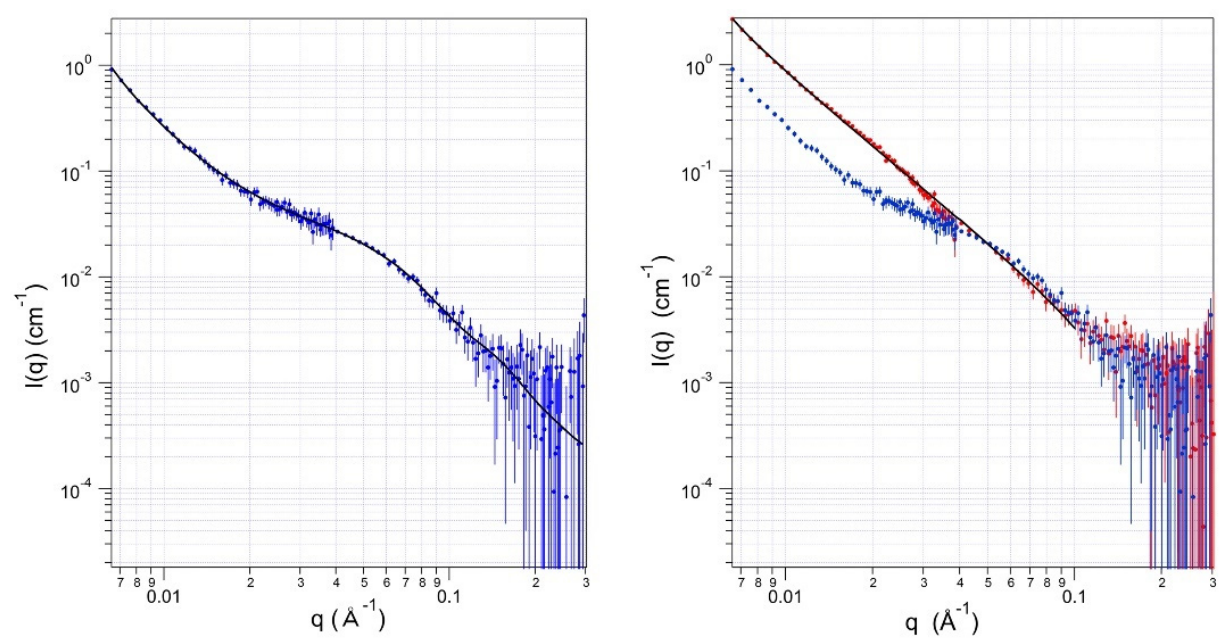

Figure 2. Small angle neutron scattering results for B. anthracis PA83 in aqueous solution at $\mathrm{pD}$ 7.8 (blue) or $\mathrm{pD} 4.9$ (red). The lines through the data are least-squares best fits of either a right parallelepiped $(\mathrm{pD} 7.8)$ or a fractal power law $(\mathrm{pD} 4.9)$. The error bars represent the standard deviations of the neutron count mean values.

\subsection{Solution Structures of PA83}

Figure 2 illustrates the SANS data for PA83 in solutions at two different $\mathrm{pD}$ values. As seen in the main plot, at pD 7.8 (blue), the scattering data between $0.045 \AA^{-1} \lesssim q \leq 0.3 \AA^{-1}$ reports on structural features in the range of $\approx 20 \AA$ to $140 \AA$. Table 1 includes the best-fit depth, width, and length of a homogeneous right parallelepiped to these data (black line). These dimensions are similar to the measured sizes of monomeric PA83 from its crystal structure [56] (Figure 3). The volume of a parallelepiped estimated from the SANS data is $18 \AA \times 63 \AA \times 71 \AA=80 \times 10^{3} \AA^{3}$, which is comparable, within one standard deviation, to a volume $=98.5 \times 10^{3} \AA^{3}$ calculated from the protein molecular mass $\left(83 \mathrm{~kg} \mathrm{~mol}^{-1}\right)$ and an assumed protein density $\left(1.4 \mathrm{~g} \mathrm{~cm}^{-3}\right)$ [57]. This volume estimate indicates that at $\mathrm{pD}$ 7.8 , the PA83 scattering unit is a monomer. The scattering data for $q \lesssim 0.1 \AA^{-1}$ are well fit by a fractal power law [58], which indicates that the solution also contains aggregates of the protein. 
Table 1. Geometrical parameters for fitting PA83 scattering at $1 \mathrm{mg} \mathrm{mL}^{-1}$ protein in $\mathrm{D}_{2} \mathrm{O}^{\mathrm{a}}$.

\begin{tabular}{ccccc}
\hline Sample/Model & Depth $(\AA)$ & Width $(\AA)$ & Length $(\AA)$ & Power Law Slope \\
\hline pD 7.8/Right parallelepiped & $18 \pm 4$ & $63 \pm 3$ & $71 \pm 4$ & $2.64 \pm 0.04$ \\
pD 4.9/Power function & - - b & -- & -- & $2.255 \pm 0.0004$ \\
\hline
\end{tabular}

a The uncertainties listed are found when the other geometric variables are held constant. ${ }^{\mathrm{b}}$ In the power law fit, the protein's Depth, Width, and Length are not determined.
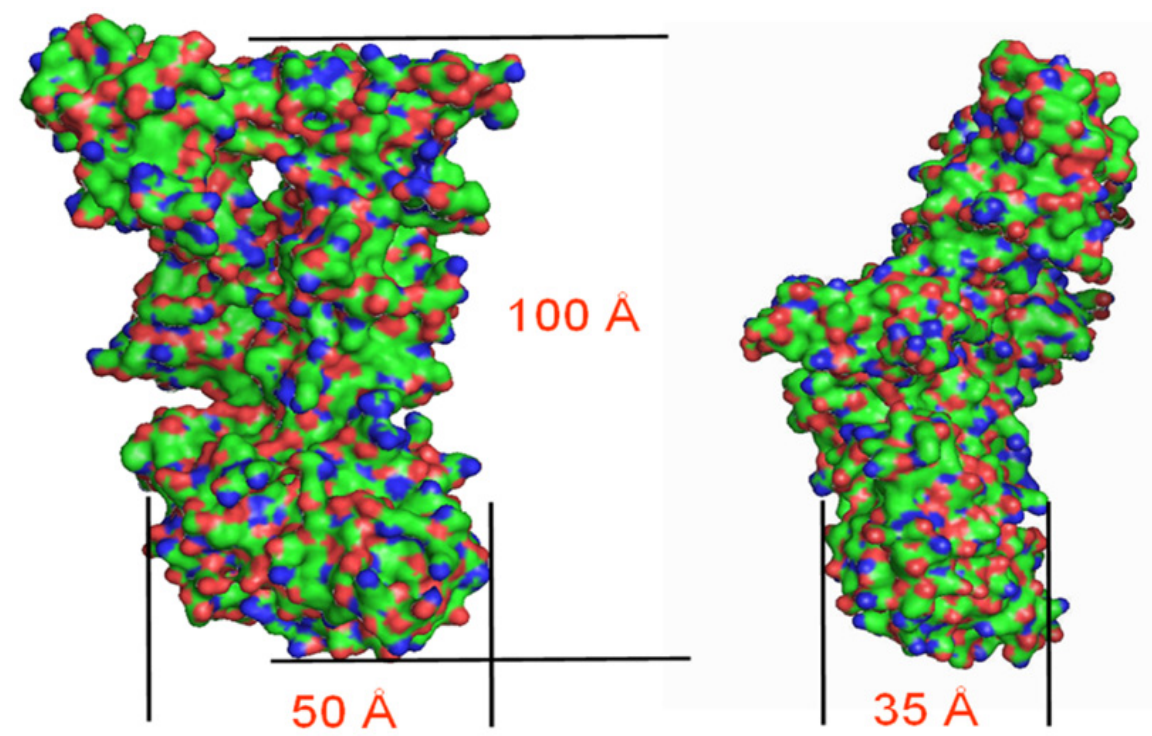

Figure 3. Perpendicular projections of the crystal structure of monomeric PA83 from the PDB (3TEY) [56].

In contrast to the data obtained at $\mathrm{pD} 7.8$, at $\mathrm{pD} 4.9$ (red), the scattering data are virtually featureless and are best fit to a straight line (power-law slope $=2.25$ ) on the log-log plot. Therefore, this suggests that PA83 forms an aggregate that is larger than the longest length of the data window, $900 \AA$ [59]. The power-law slope fits the pD 4.9 sample data for $0.007 \leq q \leq 0.1$, and the greater $q$ value is equivalent to a length of $63 \AA$, essentially the size of a PA83 monomer. The scattering at higher $q$-values arises from the molecular structure of the PA83. However, the noise level and number of points in that range prevent us from discerning a definitive, detailed structure. The minor differences in the power-law slopes at the two $\mathrm{pD}$ values could be due to an artifact of the curve-fitting. Both values are commonly found for random clustering of macromolecules [58].

\subsection{Solution Structure of PA63}

In vivo, protective antigen is secreted as the $83 \mathrm{~kg} \mathrm{~mol}^{-1}$ monomeric B-toxin, PA83. However, because PA63 allows the entry of the A-toxins LF and EF into the cytoplasm, where they interfere with two cellular pathways and cause cell death [4], PA63 itself is used as a model system for anthrax toxin mechanistic studies [5,19,20,60-63]. To understand the process of how PA63 can form channels, and to test existing structural models for it, we used SANS to study PA63 in solution.

Figure 4 shows the SANS results for PA63 at pD 7.2 for $0.02 \AA^{-1} \lesssim q \lesssim 0.25 \AA^{-1}$ (i.e., length scales between $\approx 310 \AA$ and $25 \AA$ ). Note the presence of features in the scattering data at $q \approx 0.08 \AA^{-1}$ (length scale $\approx 80 \AA$ ). The solid lines are the best fits to the data assuming either a solid cylinder (gray) or a hollow cylinder (black). The dimensions for the best-fit structures shown in Table 2 suggest that the structure is that of a heptameric complex, which is consistent with the claim that PA63 forms a stable heptamer in solution [64]. From the table, both the inner hole radius and the outer radius, found with SANS, are considerably different $(\approx 2$-fold smaller) than those obtained with cryo-EM by Ren and colleagues [27] (Figure 5A). In contrast, the SANS results for those dimensions are similar 
to those obtained with cryo-EM by Fabre et al. [28] (Figure 5B), but the heptamer's length obtained here with SANS is $\approx 25 \%$ less than was observed with cryo-EM [28].

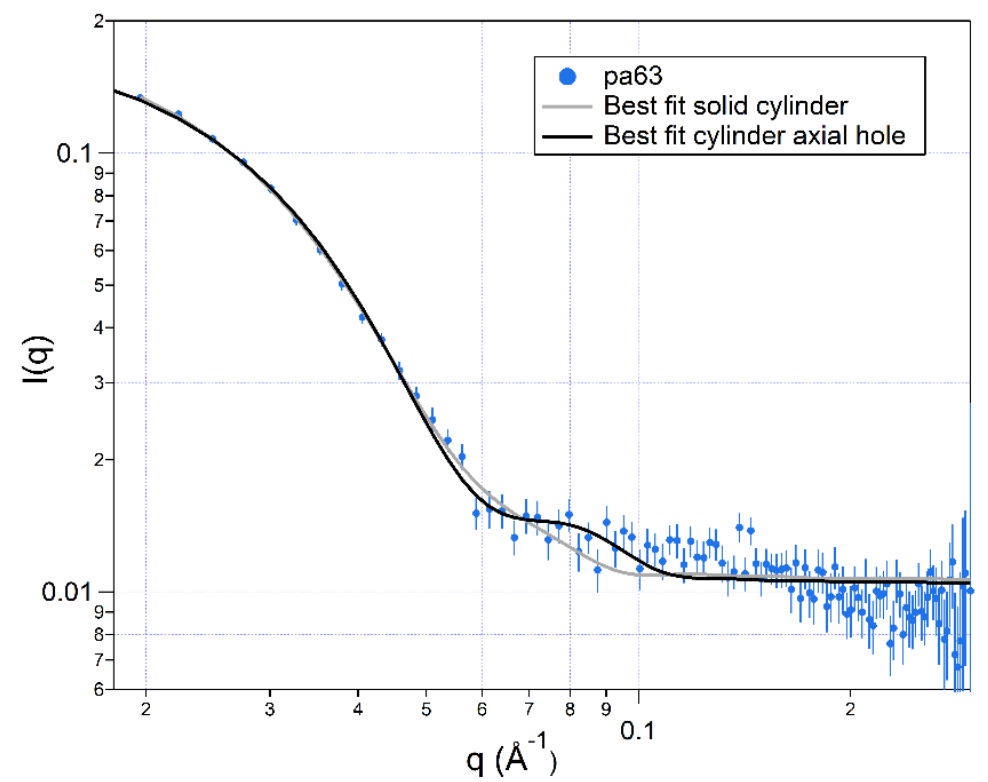

Figure 4. Small angle neutron scattering results for B. anthracis PA63 in aqueous solution. The calculated best fitting scattering curves are for a solid right cylinder (gray) or a right cylinder with an axial hole (black). The error bars represent the standard deviations of the neutron count mean values.

Table 2. Geometrical parameters for fitting PA63 scattering at $1 \mathrm{mg} \mathrm{mL}^{-1}$ protein in $\mathrm{D}_{2} \mathrm{O}$.

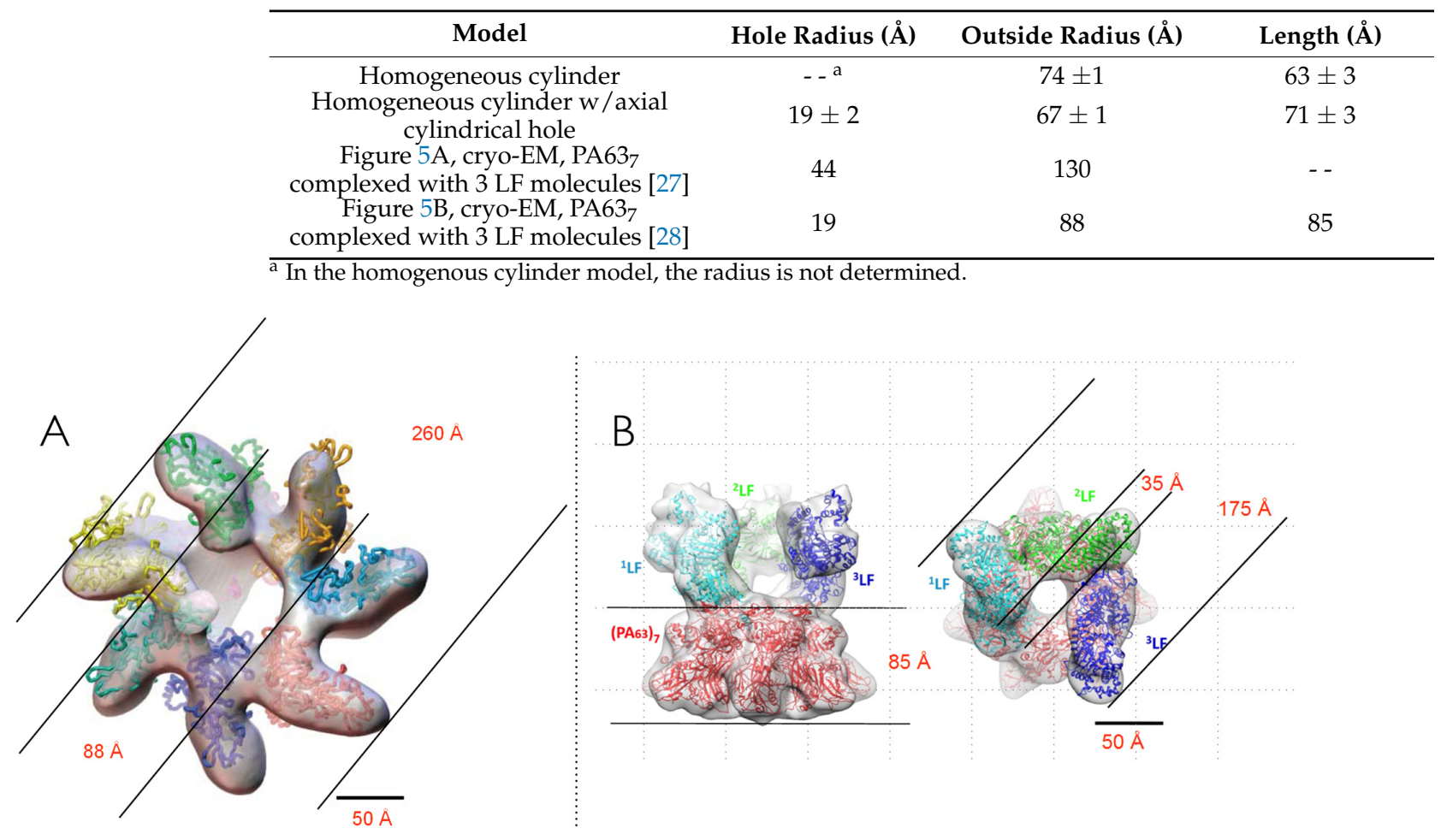

Figure 5. Two different structures of heptameric PA63 complexed to three LF proteins estimated from cryo-electron microscopy. The indicated dimensions are compared with the SANS results in Table 2. Images adapted from (A) Ren et al. [27] and (B) Fabre et al. [28]. 


\subsection{PA63 Channel Formation Kinetics Measurements}

We showed earlier that $\alpha$-HL formed channels in planar lipid bilayer membranes at nearly constant rates over long time periods at both $\mathrm{pH} 7.5$ and $\mathrm{pH} 4.5$, and that the rate was $\approx 15$-fold greater at the lower $\mathrm{pH}$ value [31]. The former result allowed us to reconstitute $\alpha$-HL into tethered bilayer membranes at a sufficiently high surface concentration for neutron reflectometry structural studies of fully-functional channels [31]. Below, we describe our attempt to reproduce this process with PA63.

\subsubsection{Channel Formation by B. anthracis PA63}

PA63 in buffered aqueous solution forms channels spontaneously when the protein is added to one of the two aqueous solutions bathing either side the planar lipid bilayer membrane $[12,13,17,19,20,65]$. However, at $\mathrm{pH} 8.5$, no conducting channels form (data not shown). At $\mathrm{pH} 7.2$ and with a constant DC applied potential, the ionic current time series in Figure 6A shows that after protein injection $(t=0)$, the current rises slowly over $16 \mathrm{~h}$. In contrast, at $\mathrm{pH} 6.6$, the current increases relatively rapidly in the first $30 \mathrm{~s}$ and more slowly thereafter. At $\mathrm{pH}$ 6.0, the initial current formation rate is similar to that at $\mathrm{pH}$ 6.6, but the current at $600 \mathrm{~s}$ is 3 -fold less. A plot of the current levels at $600 \mathrm{~s}$ for different $\mathrm{pH}$ values, relative to that at $\mathrm{pH} 6.6$, is shown in Figure $6 \mathrm{~B}$. The peak at $\approx \mathrm{pH} 6.6$ suggests there are at least two $\mathrm{pH}$-dependent processes (one increasing and one decreasing with $\mathrm{pH}$ ) that control PA63 channel formation. Electrochemical impedance spectroscopy was used to confirm that the decrease in the channel insertion rate also occurs in a tethered bilayer membrane on a solid support prepared as described previously in our $\alpha$-HL structural study [31] (data not shown).
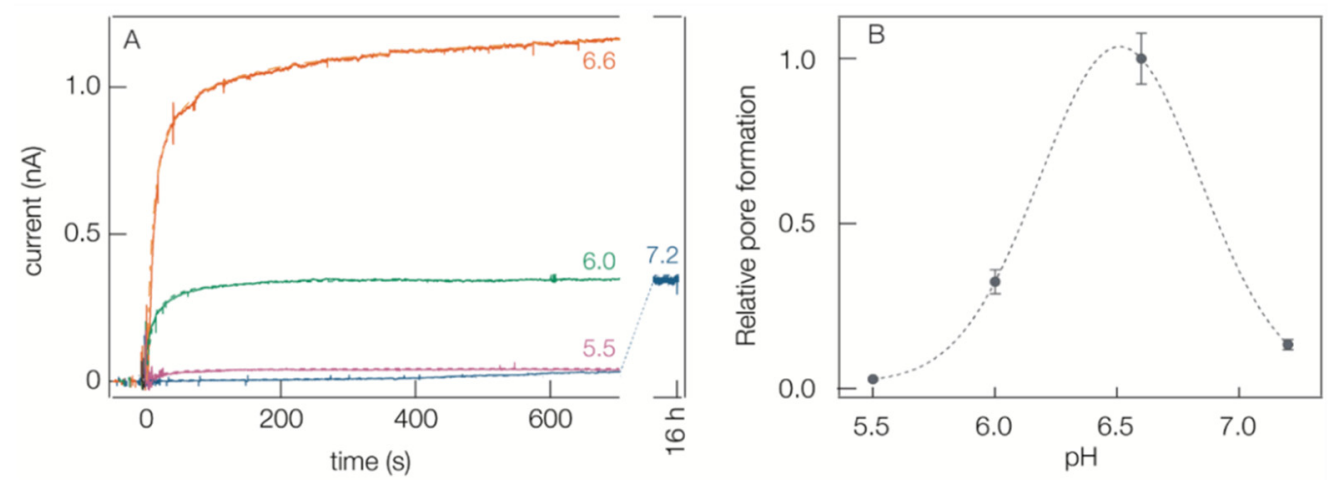

Figure 6. $\mathrm{pH}$ dependence of pore formation by B. anthracis protective antigen 63 (PA63). (A) Ionic transmembrane current time series following an injection of PA63 at $t=0$ into the aqueous phase bathing one side of the lipid bilayer membranes. The aqueous solutions were at either $\mathrm{pH} 7.2$ (blue), 6.6 (orange), 6.0 (green), or 5.5 (purple), and the applied potential was $+10 \mathrm{mV}$ DC. (B) $\mathrm{pH}$ dependence of pore formation estimated from the current value at $600 \mathrm{~s}$ (the dashed line is drawn to guide the eye). The error bars represent the standard deviations of 4 to 7 replicates of experiments on new membranes with fresh PA63 added to the chamber.

\subsubsection{AC Current Measurement}

The most striking feature in the ionic current (Figure 6A) is the near cessation of channel formation within $\approx 1$ min after adding PA63 to the bilayer chamber. However, for times greater than $1 \mathrm{~min}$, the current does not quite reach a steady state, which we thought might be due, in part, to an electrode polarization artifact. We, therefore, repeated the electrophysiology experiments with a $10 \mathrm{~Hz}$ sinusoidal applied potential and obtained essentially the same results (Figure 7). The difference in the positive and negative voltage components is likely due to voltage-dependent channel-formation rates, the non-linear I-V relationship of the PA63 channel [12], and/or a small electrode offset. 


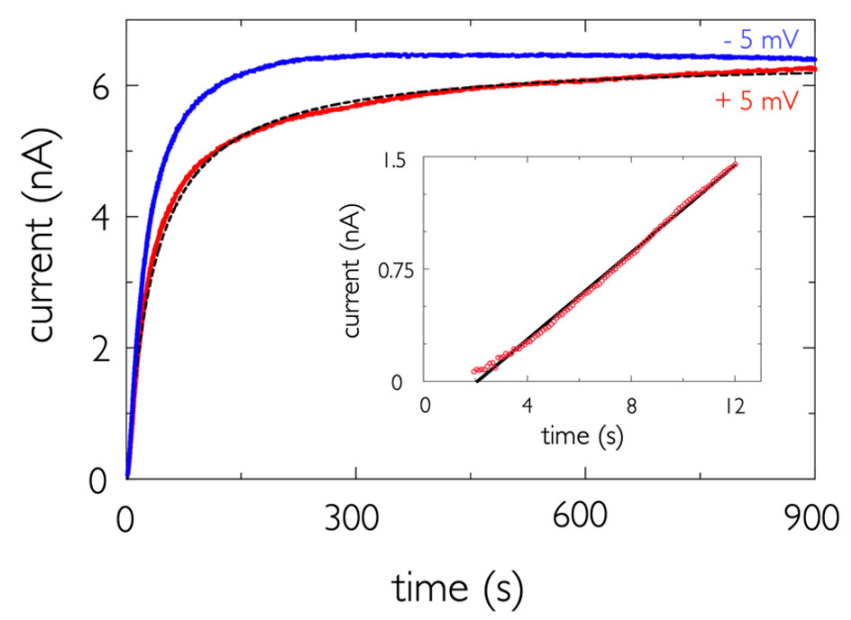

Figure 7. The absolute values for the resistive component of the ionic current estimated with peak applied voltages $V_{\text {applied }}=+5 \mathrm{mV}$ (red) or $-5 \mathrm{mV}$ (blue) $(10 \mathrm{mV}$ peak-to-peak sine wave input potential) at $\mathrm{pH} 5.5$ and an initial concentration of PA63 of $10 \mathrm{nM}$. A least-squares fit to a model that assumes the decrease in channel formation rate is caused by $\mathrm{PA} 63_{7}$ dimerization in solution (see text below) to the $+5 \mathrm{mV}$ data is also shown (dashed black curve). (Inset): A plot of the initial ionic current time series for $V=+5 \mathrm{mV}$ with a linear regression fit to the data (black line).

\subsubsection{PA63 Channel Formation Kinetics}

To describe the ion current kinetics, we next consider simple models for channel formation by PA63. PA63 increases the planar lipid bilayer conductance by forming nanometer-scale pores or channels in the membrane $[12,13,17,19,20,65]$. If we assume that each channel in the membrane acts independently of the others, the total current is simply:

$$
I(t)=i_{s c} N(t)
$$

where $N(t)$ is the number of channels in the membrane at time $t$, and $i_{s c}$ is the current per (single) channel at a given applied potential. Given that the channels form within seconds of protein addition, diffusion of the protein from the bulk is not rate-limiting (which is discussed below). Thus, the rate of channel formation is assumed to be proportional to the bulk concentration of the channel forming unit, $C(t)$,

$$
\frac{d N(t)}{d t}=k_{m} C(t)
$$

where $k_{m}$ is an apparent rate constant for channel insertion into the membrane (number of channels $\mathrm{M}^{-1} \mathrm{~s}^{-1}$ ). If we assume there is no significant loss of protein due to aggregation, binding to the electrophysiology chamber walls, etc., then $C(t)$ is a constant $\left(C_{0}\right)$, and the ionic current would be:

$$
I(t)=i_{s c} k_{m} C_{0} t
$$

For simplicity, we assume that the channel forming unit is a PA63 heptamer [64] (Equation (4)), that channels form when PA63 heptamers in solution bind to the membrane (Equation (5)),

$$
\begin{gathered}
7 \text { PA63 }_{\text {solution }} \stackrel{k_{h}}{\rightarrow} \text { PA63 } 3_{7, \text { solution, }} \\
\text { PA63 } 6 \text {,solution }+ \text { membrane } \stackrel{k_{m}}{\rightarrow} P A 63_{7, \text { membrane }}
\end{gathered}
$$

and these reactions proceed irreversibly. PA63, solution and PA637,membrane denote PA63 heptamers in solution or associated with the membrane, respectively. The SANS data for PA63 (Figure 4) shows that some of the PA63 in solution has dimensions consistent with a heptamer. We further assume that the heptamers form instantaneously when PA63 is added to the aqueous solution, which has a lesser $\mathrm{pH}$ value than that of the stock solution. 
Equation (3) is consistent with $\alpha$-HL channel experimental data [31] and also with the initial channel formation results reported here with PA63 (Figure 7, inset). The least-squares linear fit to this data shows that the slope is $\approx 0.145 \mathrm{nA} \mathrm{s}^{-1}$. Because the single-channel current is $i_{s c} \approx 0.4 \mathrm{pA}$ under these conditions [19], and we assume the initial heptamer concentration as $1 / 7$ of the initial monomer concentration (i.e., [PA637] $(0)=10 \mathrm{nM} / 7=1.42 \mathrm{nM}$ ), then $k_{m}=2.7 \times 10^{11}$ channels $\mathrm{M}^{-1} \mathrm{~s}^{-1}$. In addition, channels are initially inserted into the membrane at a rate provided by the fitted slope divided by the single-channel current: $0.145 \mathrm{nA} \mathrm{s}^{-1} / 0.4 \mathrm{pA}$ channel ${ }^{-1} \approx 362$ channels s$^{-1}$.

If the reactions in Equations (4) and (5) were the only processes to occur, because the number of functional channels in the membrane is much greater than the number of proteins in solution, the protein concentration in solution should remain unchanged, and the current should increase linearly with time (Equation (3)). Because that is clearly not the case (Figures 6A and 7 main plot), additional reaction schemes, which account for a decrease in either the channel formation rate or the number of functional channels (or both), are needed to describe the channel formation kinetics.

The channel formation rate, and thus the rate of change of ionic current, would decrease if the concentration of PA63 molecules in the bulk solution decreased. That could be caused by aggregation of PA63 heptamers in solution (as dimers and/or higher-order structures, as is indicated by part of the SANS data in Figure 4) or due to PA63 heptamers binding to and blocking existing PA63 channels. These irreversible schemes are described by Equations (6) and (7), respectively.

$$
\begin{gathered}
2 \text { PA63 } 7 \text {,solution } \stackrel{k_{D}}{\rightarrow}\left(P A 63_{7}\right)_{2, \text { solution }} \\
P A 63_{7, \text { solution }}+\{P A 63\}_{7, \text { channel }} \stackrel{k_{I}}{\rightarrow}\{P A 63\}_{\text {inactivated channel }}
\end{gathered}
$$

where $k_{D}$ and $k_{I}$ are forward rate constants. The reaction in Equation (7) is ruled out by inspection because if it were the sole cause of the time-dependent decrease of the channel formation rate, that would require a near-perfect balance between the channel formation and channel blocking rates to occur only after the first minute of channel formation, which is unlikely.

For simplicity, we further assume that the decrease of the PA63 7 concentration in solution is caused solely by the formation of heptameric dimers (Equation (6)), although additional oligomerization or clustering of the protein may occur, as seen here with SANS, but we ignore that possibility here. Thus, the rate of change of the PA63 7 concentration due to dimer formation in the bulk, $C(t)$, can be written as:

$$
\frac{d C(t)}{d t}=-k_{D} C(t)^{2}
$$

The solution to this differential equation is:

$$
C(t)=\frac{C_{0}}{1+k_{D} C_{0} t}
$$

where $C_{0}$ is the initial bulk concentration of PA637.

Substituting Equation (9) into Equation (3) results in the ionic current time dependence:

$$
I(t)=\frac{i_{s c} k_{m} C_{0} t}{1+k_{D} C_{0} t}
$$

As $t \rightarrow \infty$, a predicted complete loss of $\mathrm{PA}_{63} 3_{7}$ in solution would cause the current to asymptote towards a steady-state value $I(\infty)=i_{s c} k_{m} / k_{D}$, which closely resembles the observed trends (Figures 6A and 7 main plot).

A least-squares fit of Equation (10) to the current (with $+5 \mathrm{mV}$ applied potential) is shown in Figure 7 (dashed black line), and the goodness of fit parameter is $r^{2}=0.995$. The 
value of $k_{m}=3.5 \times 10^{11}$ channels $\mathrm{M}^{-1} \mathrm{~s}^{-1}$ determined from the non-linear fit over the entire range of data $(\approx 900 \mathrm{~s})$ is surprisingly close to the value determined from the linear fit to the initial current rise (only $\approx 1.7$-fold greater than $k_{m} \approx 2.7 \times 10^{11}$ channels $\mathrm{M}^{-1} \mathrm{~s}^{-1}$ obtained from the linear fit to the initial current recording, see above), which is remarkable. We therefore, conclude that the simple dimerization model is reasonable. In addition, the fit of Equation (10) to the data shows that $k_{D}=2.2 \times 10^{7} \mathrm{M}^{-1} \mathrm{~s}^{-1}$. We are currently studying the experimental dependence of $k_{m}$ and $k_{D}$ with the initial PA63 concentration.

From Equations (2) and (9), the channel formation rate is:

$$
d N(t) / d t=\frac{k_{m} C_{0}\left(1-k_{D} C_{0} t /\left(1+k_{D} C_{0} t\right)\right)}{1+k_{D} C_{0} t}
$$

Using the non-linear fit parameters for $k_{m}$ and $k_{D}$, at $t=5 \mathrm{~s}$, the channel formation rate is 371 channels s${ }^{-1}$, which is in good agreement with the estimate obtained from the linear fit to the early time ion current data above ( 362 channels s ${ }^{-1}$ ), suggesting that the initial-rate calculation was robust.

Because the solved expression for the channel current (Equation (10)) looks similar to a non-time dependent Langmuir adsorption isotherm [66], one might think that the channel formation rate decreases asymptotically within $10 \mathrm{~min}$ because the number of channel binding sites left are vanishingly small. However, that can be ruled out because, at the level of nearly saturated current (Figure 7), the channels only occupy $\approx 10^{-3} \%$ of the membrane surface. It is also conceivable that the channel formation process nearly ceases because of competitive binding between channel-forming $\mathrm{PA}_{63}{ }_{7}$ and inactive protein).

To test both hypotheses, we made sequential injections of fresh PA63 to the same bilayer chamber compartment in a single membrane experiment (Figure 8). The data show that the addition of a new protein causes new channel formation with the same qualitative kinetics trend and magnitude increase in the current, which clearly demonstrates that the channel formation cessation is not caused by the loss of channel binding sites in the membrane.

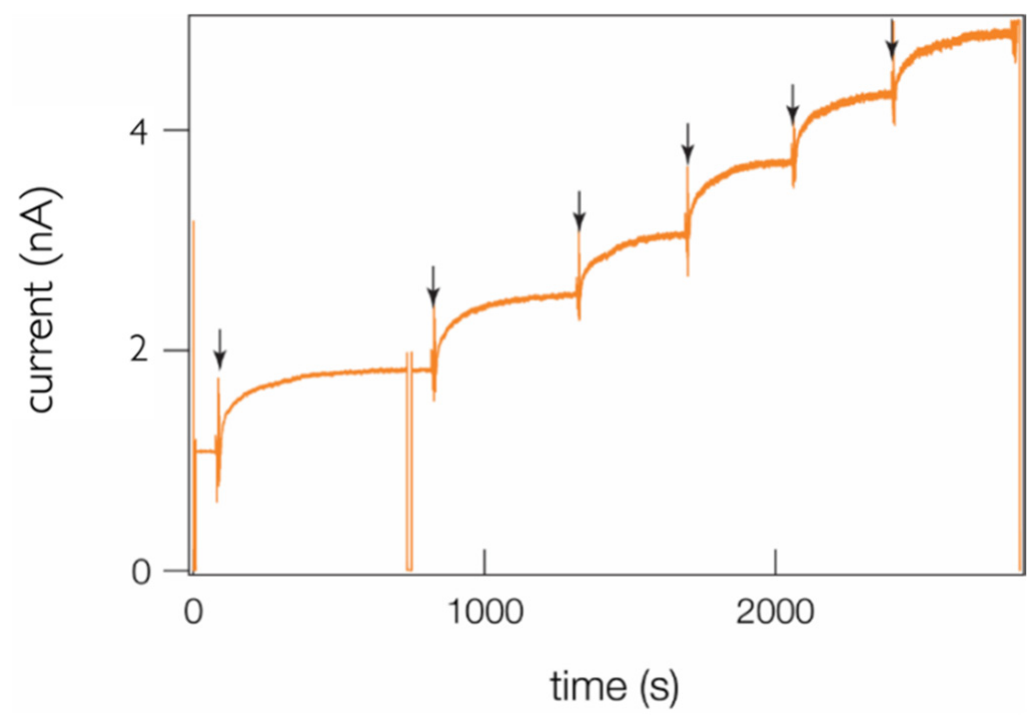

Figure 8. Sequential additions of fresh PA63 (arrows) cause new channel formation. Aliquots of $1 \mathrm{nM}$ stock PA63 solution were added to one of the two aqueous phases bathing the membrane. The transient current drop at $t \approx 750 \mathrm{~s}$ was caused by a brief change to the applied potential (to check for electrode polarization). Variations in the current responses were caused by slight differences in the stirring duration and the time between sequential additions of fresh PA63 stock solution to the bilayer chamber. 


\section{Discussion}

The solution structures of the two B. anthracis protective antigen proteins, full-length PA83, and its proteolytically cleaved product PA63, were determined with small angle neutron scattering. At pD 4.9, most of the PA83 scattering data are described by a linear slope described by a fractal power law, which indicates that most of the protein formed aggregates over a wide length scale. At pD 7.8, PA83 is a monomer and was modeled as a right parallelepiped with a volume $\approx 124 \times 10^{3} \AA^{3}$, similar to the volume estimated from its molecular mass and a typical protein density value. Some residual aggregate remains.

At pD 7.2, the PA63 SANS data were fit by a right circular cylinder with an axial through-hole. The structure is inconsistent with a cryo-EM structure of $\mathrm{PA}_{63} 3_{7}$ bound to three LF molecules by Ren and colleagues [27] but similar to the structure of PA637, also bound to three LF molecules, obtained by Fabre et al. [28].

With the goal of studying the interaction of the PA63 channel with B. anthracis lethal factor and edema factor with neutron reflectometry, as had been done for another ion channel [31], we determined the ability of PA63 to form channels in planar lipid membranes. Like its structural analog, the $S$. aureus $\alpha$-HL toxin, which spontaneously forms channels in membranes at nearly complete surface coverage, PA63 also initially forms channels, but unlike $\alpha$-HL, another process occurs with a time constant of $\approx 1$ min that inhibits subsequent channel insertion. This latter phenomenon will have to be significantly reduced or eliminated to use NR for structural studies of the PA63 7 channel itself, of the two A toxins (LF or EF) bound to the channel, and of small molecules that inhibit the binding of $\mathrm{LF}$ and EF to the channel.

The electrophysiology experiments were performed by vigorously stirring the solution for several seconds when the protein was added, and we assumed the protein was well dispersed by that process. The short delay (several seconds) after protein addition to the chamber suggested that complications to the ionic current kinetics due to diffusion of channel-forming units through the unstirred layer of solution adjacent to the membrane could be ignored at this time [67-71].

In the chemical kinetics scheme above (Equations (6), (8) and (10)), we suggested that the loss of channel-forming protein is caused initially by dimerization of PA63 3 in solution. Higher-order oligomerization in solution is currently beyond the ability of these electrophysiology experiments to discern. Nevertheless, if dimers are formed via contacts between neighboring heptamer cap domains, as is illustrated by the cartoon in Figure 9A, it is conceivable that the addition of an excess of $B$. anthracis LF or EF (or perhaps small molecules that act as therapeutic agents against anthrax toxin infections [12]) could inhibit $\mathrm{PA}_{63}$ dimerization (Figure 9B) and thereby allow for a greater concentration of PA63 channels per unit area in the membrane as desired for neutron reflectometry experiments. We are exploring this possibility.

We are also investigating (a) the stoichiometry of channel-forming units (using fluorescence-based single-molecule experiments), (b) the concentration dependence of the initial channel-formation kinetics, and (c) whether PA63 ${ }_{7}$ in solution decreases because it binds to the excess lipid in the chamber, an artifact that is possible given the membrane formation method used here [72]. 


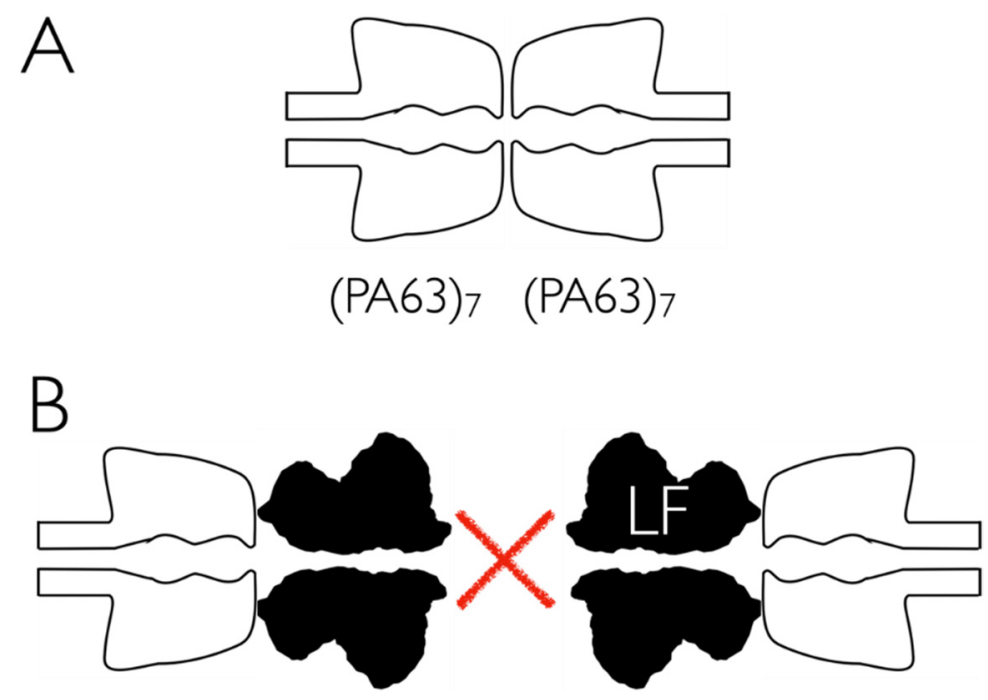

Figure 9. Cartoon of a possible method to inhibit the dimerization of PA63 heptamers in solution. (A) With PA63 heptamers only, the protein is assumed to oligomerize (dimerization shown here). (B) If, instead, PA63 is added to an aqueous solution that contains an excess of B. anthracis LF or EF, the binding of either to the channel cap domain may interfere with the formation of dimers, or perhaps even larger oligomers. The transmembrane $\beta$-barrel segment is depicted here in a non-extended configuration.

\section{Conclusions}

Our results show that at near-neutral $\mathrm{pH}, \mathrm{PA} 83$ is a monomer in solution (it does not oligomerize as is assumed to occur on membrane-bound receptors). However, the SANS data also show that the cleaved form of PA83, PA63, forms oligomers in solution that have the same dimensions as heptamers (as judged by cryo-EM), which suggests that heptamer formation by PA63 does not critically depend on being bound to a lipid membrane. In addition, the results of the ion channel kinetic experiments demonstrate that reactions in solution prevent all the heptamers from inserting into the membrane. As a result, a different experimental protocol is needed to keep PA63 in a form that can insert unimpeded for intervals in excess of minutes.

\section{Materials and Methods}

\subsection{Small Angle Neutron Scattering (SANS) of PA83 and PA63 Proteins in Solution}

Recombinant $B$. anthracis protective antigen 63 (PA63, List Biological Laboratories, Campbell, CA, USA) was added to $99.9 \% \mathrm{D}_{2} \mathrm{O}$ (Cambridge Isotope Labs, Tewksbury, MA, USA) to make a solution of $1.0 \mathrm{mg} \mathrm{mL}^{-1}$ in the protein. The final solution additionally had $10 \mathrm{mM}$ bisTris propane, $\mathrm{pD} 8.5$, and $1.25 \%$ trehalose. Recombinant $B$. anthracis protective antigen 83 (PA83, List Biological Laboratories) was dissolved in $95 \% \mathrm{D}_{2} \mathrm{O}$ to $1 \mathrm{mg} \mathrm{mL}^{-1}$, which, with the material's 5 mM HEPES buffer, made the solution $\mathrm{pD} 7.8$. Acetate buffer was used to make the pD 4.9 solution. The PA83 solutions also contained $50 \mathrm{mM} \mathrm{NaCl}$ from the original lyophilized material.

\subsection{SANS Data Collection}

The $1 \mathrm{mg} \mathrm{mL} \mathrm{m}^{-1}$ solution was held in a $(1.00 \pm 0.01) \mathrm{mm}$ path-length cylindrical silica spectrometry cell (Hellma, Plainview, NY, USA) with a volume $\approx 320 \mu \mathrm{L}$. SANS measurements were performed on the NG3 and NG7 30 m SANS instruments at the NIST Center for Neutron Research (NCNR) in Gaithersburg, MD, USA [73]. Data was collected for the protein solutions and the $\mathrm{D}_{2} \mathrm{O}$ buffer at ambient temperature. SANS was measured using cold neutrons with wavelength $\lambda=6.0 \AA$, and $\Delta \lambda / \lambda=0.11$.

Scattered neutrons were detected with a $64 \mathrm{~cm} \times 64 \mathrm{~cm}$ two-dimensional positionsensitive detector with $(128 \times 128)$ pixels with $0.5 \mathrm{~cm}$ pixels. Raw counts for each pixel 
were put on the same relative scale by normalizing to an incident beam monitor count made by a detector in parallel with the data collection. The scattering was then corrected for a non-uniform detector response. Data were placed on an absolute scale by normalizing the scattering intensity to the measured incident beam flux. The data were then radially averaged to produce the scattering curves of $\log _{10} I(q)$ versus $\log _{10} q$, where $I(q)$ is the scattering intensity, $q=(4 \pi \lambda) \sin \theta$ is the momentum transfer, $\lambda$ is the neutron wavelength, and $2 \theta$ is the scattering angle measured from the axis of the incoming neutron beam. Two camera positions were used for PA83: $2 \mathrm{~m}$ and $10 \mathrm{~m}$. The sample-to-detector position at $2.0 \mathrm{~m}$ had a $20 \mathrm{~cm}$ beam stop offset, which, with the $6.0 \AA$ wavelength, provides a $q$ range $0.006 \AA<q<0.3 \AA^{-1}$, equivalent to a length range of $\approx 900 \AA$ to $\approx 21 \AA$.

The PA83 and PA63 scattering data were corrected for the $\mathrm{D}_{2} \mathrm{O}$ background by subtracting the scattering from the $\mathrm{D}_{2} \mathrm{O}$ buffer alone. No solute-volume correction was needed for the $1 \mathrm{mg} \mathrm{mL}^{-1}$ because any adjustment would be less than $0.1 \%$, which is within the uncertainties of the scattering amplitudes. PA83 scattering data were collected at pD 7.8 and 4.9. Under the conditions used here, the measured $\mathrm{pH}$ and $\mathrm{pD}$ are the same [74].

\subsection{SANS Curve Fitting}

The scattering curves were fit using Igor Pro software with fitting macros developed at the NCNR [75]. For PA63, two geometric models were compared: either a homogeneous cylinder (two geometric variables) or a homogeneous cylinder with an axial hole (three geometric variables). All scattering curve fittings account for the neutron optics by a smearing algorithm and assigning the flat, incoherent background left after subtracting the buffer scattering. For PA83, the geometry of solitary molecules was modeled as a right parallelepiped, and, where appropriate, a fractal slope model was applied.

\subsection{Electrophysiology: Membrane Formation and Channel Activity}

Electrolyte solutions were prepared with $0.1 \mathrm{M} \mathrm{KCl}, 10 \mathrm{mM}$ of a buffering agent, and either 2-( $N$-morpholino)ethanesulfonic acid, 3-(N-morpholino)propanesulfonic acid, sodium phosphate, or sodium dihydrogen phosphate in $18.2 \mathrm{M} \Omega \mathrm{cm}$ water (UHQ reagentgrade purification system Millipore, Billerica, MA, USA). The solution $\mathrm{pH}$ was adjusted with either citric acid or hydrochloric acid (Sigma-Aldrich, St. Louis, MO, USA).

The "solvent-free" phospholipid bilayer membranes [72] were formed with 1,2-diphytanoyl-sn-glycero-3-phosphocholine (DiPhyPC; Avanti Polar Lipids, Inc., Birmingham, AL, USA), in high purity pentane (Burdick and Jackson, Muskegon, MI, USA) on $\mathrm{a} \approx 100 \mu \mathrm{m}$ diameter hole in a $17 \mu \mathrm{m}$ thick Teflon partition that separated two $2.5 \mathrm{~mL}$ Teflon wells [44]. A transmembrane potential was applied via two matched $\mathrm{Ag} / \mathrm{AgCl}$ electrodes (In Vivo Metric, Healdsburg, CA, USA) separated from the solution by Vycor glass frits (Koslow Scientific Company, Englewood, NJ, USA). The current was converted to voltage and amplified with an Axon Instruments 200B patch-clamp amplifier (Molecular Devices, Sunnyvale, CA, USA) in the voltage-clamp mode and then digitized with an Axon 1440 16-bit analog to digital converter. The PA63 was injected from a $1 \mathrm{mg} \mathrm{mL}^{-1}$ stock solution to the indicated concentrations (Figures 6-8) with the solution vigorously stirred for several seconds with Teflon-coated magnetic flea bars. A FORTRAN program was written to remove the header, minimize the stirring artifacts, and check for drift in the conductance at the end of each run. The data was typically saved as 2-byte integers (binary), in some cases median filtered and subsequently scaled to the correct ionic current values. Some of the current time series data were fitted to chemical kinetic models using TableCurve 2D (Systat, San Jose, CA, USA). To increase the dynamic range of the current recordings, the data in Figure 7 were initially acquired with a high-gain setting, and when the current was close to saturating the patch-clamp amplifier, the gain was lowered to the next setting. This was repeated several times over the course of each experiment.

Figure 10 shows a cartoon illustration of the electrophysiology setup. In most cases, the applied potential was direct current, and positive potentials were defined in reference to the virtual ground on the side opposite to which the protein was added (i.e., positive 
potentials drive cations into the cap domain side of the channel). To test for the effects of voltage-induced channel inactivation and electrode polarization, we also employed a $10 \mathrm{~Hz}$ sine wave alternating voltage across the membrane. For those experiments, an additional program was written to extract the resistive component of the current.

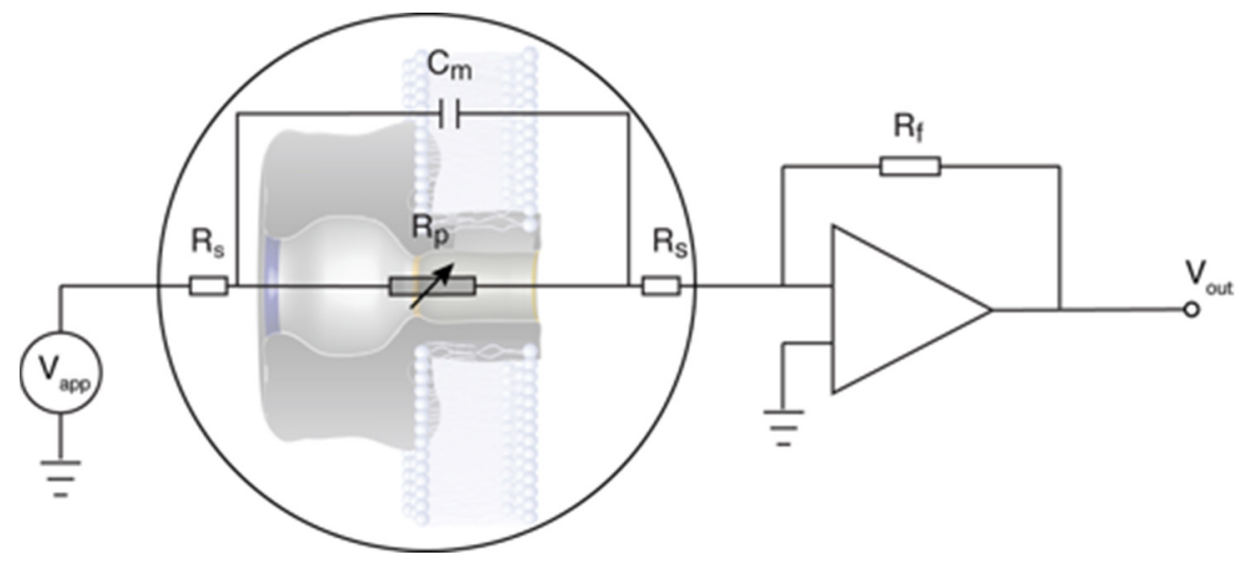

Figure 10. Illustration and electrical circuit analog of the electrophysiology experiments. For DC applied potentials, the membrane capacitance $\left(C_{m}\right)$ and the Teflon membrane support capacitance (not shown) in parallel with $\mathrm{C}_{\mathrm{m}}$ have no effect on the DC current. However, for time-varying applied potentials, the total capacitance is sufficiently large for the capacitive reactance to contribute appreciably to the time-varying current. The membrane current is converted to a voltage $\left(\mathrm{V}_{\text {out }}\right)$ via a FET amplifier with a feedback resistor $\left(R_{f}\right)$. The DC series resistance, $R_{s}$, due to the electrodes and electrolyte solution is much less than the resistance of the PA63 channels in the membrane (i.e., $R_{\mathrm{s}} \ll R_{\mathrm{p}}$ ).

Author Contributions: Conceptualization, J.J.K. and K.A.R.; Data curation, A.M.-R., K.A.R. and J.J.K.; Formal analysis, K.A.R. and J.J.K.; Funding acquisition, J.J.K.; Investigation, A.M.-R., K.A.R., V.S. and J.J.K.; Methodology, K.A.R. and J.J.K.; Project administration, J.J.K.; Software, J.J.K.; Supervision, J.J.K.; Writing—original draft, A.M.-R., K.A.R. and J.J.K.; Writing—review \& editing, K.A.R. and J.J.K. All authors have read and agreed to the published version of the manuscript.

Funding: This work was supported in part by a NRC/NIST Postdoctoral Fellowship (to A.M.-R.), the NIST Office of Law Enforcement Standards (to J.J.K.), a Marie Skłodowska-Curie Senior Fellowship (to J.J.K.), and the Freiburg Institute for Advanced Studies (to J.J.K.) and access to SANS instruments was provided by the Center for High Resolution Neutron Scattering, a partnership between the National Institute of Standards and Technology and the National Science Foundation under Agreement No. DMR-1508249.

Institutional Review Board Statement: Not applicable.

Informed Consent Statement: Not applicable.

Data Availability Statement: Raw SANS data were generated at the NIST Center for Neutron Research. Data can be accessed at https://ncnr.nist.gov/ncnrdata/view/icpbrowser.html?pathlist= ncnrdata+ngb30sans+NGB30SANS13. Reduced and corrected SANS scattering data supporting the findings of this study are available from the corresponding authors upon reasonable request.

Acknowledgments: We thank Susan Kreuger, Joseph Curtis, and Dianne Poster at NIST for helpful comments. Contribution in part of the National Institute of Standards and Technology USA. Not subject to US copyright.

Conflicts of Interest: The authors declare no conflict of interest.

\section{References}

1. Hille, B. Ion Channels of Excitable Membranes, 3rd ed.; Sinauer Associates: Sunderland, MA, USA, 2001.

2. Ashcroft, F.M. Ion Channels and Disease; Academic Press: Cambridge, MA, USA, 1999; ISBN 9780080535210. 
3. Kasianowicz, J.J. Introduction to Ion Channels and Disease. Chem. Rev. 2012, 112, 6215-6217. [CrossRef]

4. Collier, R.J.; Young, J.A. Anthrax Toxin. Annu. Rev. Cell Dev. Biol. 2003, 19, 45-70. [CrossRef]

5. Young, J.A.; Collier, R.J. Anthrax Toxin: Receptor Binding, Internalization, Pore Formation, and Translocation. Annu. Rev. Biochem. 2007, 76, 243-265. [CrossRef] [PubMed]

6. Bradley, K.A.; Mogridge, J.; Mourez, M.; Collier, R.J.; Young, J.A.T. Identification of the Cellular Receptor for Anthrax Toxin. Nat. Cell Biol. 2001, 414, 225-229. [CrossRef]

7. Gordon, V.M.; Klimpel, K.R.; Arora, N.; A Henderson, M.; Leppla, S.H. Proteolytic Activation of Bacterial Toxins by Eukaryotic Cells is Performed by Furin and by Additional Cellular Proteases. Infect. Immun. 1995, 63, 82-87. [CrossRef]

8. Milne, J.C.; Furlong, D.; Hanna, P.C.; Wall, J.S.; Collier, R.J. Anthrax protective antigen forms oligomers during intoxication of mammalian cells. J. Biol. Chem. 1994, 269, 20607-20612. [CrossRef]

9. Milne, J.C.; Collier, R.J. pH-Dependent Permeabilization of the Plasma Membrane of Mammalian Cells by Anthrax Protective Antigen. Mol. Microbiol. 1993, 10, 647-653. [CrossRef] [PubMed]

10. van der Goot, G.; Young, J.A. Receptors of Anthrax Toxin and Cell Entry. Mol. Asp. Med. 2009, 30, 406-412. [CrossRef]

11. Ascenzi, P.; Visca, P.; Ippolito, G.; Spallarossa, A.; Bolognesi, M.; Montecucco, C. Anthrax Toxin: A Tripartite Lethal Combination. FEBS Lett. 2002, 531, 384-388. [CrossRef]

12. Halverson, K.M.; Panchal, R.; Nguyen, T.L.; Gussio, R.; Little, S.F.; Misakian, M.; Bavari, S.; Kasianowicz, J.J. Anthrax Biosensor, Protective Antigen Ion Channel Asymmetric Blockade. J. Biol. Chem. 2005, 280, 34056-34062. [CrossRef]

13. Panchal, R.G.; Halverson, K.M.; Ribot, W.; Lane, D.; Kenny, T.; Abshire, T.G.; Ezzell, J.W.; Hoover, T.A.; Powell, B.; Little, S.; et al. Purified Bacillus anthracis Lethal Toxin Complex Formed in vitro and During Infection Exhibits Functional and Biological Activity. J. Biol. Chem. 2005, 280, 10834-10839. [CrossRef]

14. Neumeyer, T.; Tonello, F.; Molin, F.D.; Schiffler, B.; Benz, R. Anthrax Edema Factor, Voltage-dependent Binding to the Protective Antigen Ion Channel and Comparison to LF Binding. J. Biol. Chem. 2006, 281, 32335-32343. [CrossRef]

15. Zhang, S.; Finkelstein, A.; Collier, R.J. Evidence that Translocation of Anthrax Toxin's Lethal Factor is Initiated by Entry of its N Terminus into the Protective Antigen Channel. Proc. Natl. Acad. Sci. USA 2004, 101, 16756-16761. [CrossRef]

16. Krantz, B.A.; Melnyk, R.A.; Zhang, S.; Juris, S.J.; Lacy, D.B.; Wu, Z.; Finkelstein, A.; Collier, R.J. A Phenylalanine Clamp Catalyzes Protein Translocation Through the Anthrax Toxin Pore. Science 2005, 309, 777-781. [CrossRef]

17. Blaustein, R.; Lea, E.J.; Finkelstein, A. Voltage-Dependent Block of Anthrax Toxin Channels in Planar Phospholipid Bilayer Membranes by Symmetric Tetraalkylammonium Ions. Single-Channel Analysis. J. Gen. Physiol. 1990, 96, 921-942. [CrossRef]

18. Blaustein, R.; Finkelstein, A. Voltage-Dependent Block of Anthrax Toxin Channels in Planar Phospholipid Bilayer Membranes by Symmetric Tetraalkylammonium Ions. Effects on Macroscopic Conductance. J. Gen. Physiol. 1990, 96, 905-919. [CrossRef] [PubMed]

19. Nablo, B.J.; Halverson, K.M.; Robertson, J.; Nguyen, T.L.; Panchal, R.; Gussio, R.; Bavari, S.; Krasilnikov, O.V.; Kasianowicz, J.J. Sizing the Bacillus anthracis PA63 Channel with Nonelectrolyte Poly(Ethylene Glycols). Biophys. J. 2008, 95, 1157-1164. [CrossRef]

20. Nablo, B.J.; Panchal, R.G.; Bavari, S.; Nguyen, T.L.; Gussio, R.; Ribot, W.; Friedlander, A.; Chabot, D.; Reiner, J.E.; Robertson, J.W.F.; et al. Anthrax Toxin-Induced Rupture of Artificial Lipid Bilayer Membranes. J. Chem. Phys. 2013, 139, 065101. [CrossRef]

21. Perutz, M.F.; Rossmann, M.G.; Cullis, A.F.; Muirhead, H.; Will, G.; North, A.C.T. Structure of Hæmoglobin: A Three-Dimensional Fourier Synthesis at 5.5- $\AA$. Resolution, Obtained by X-Ray Analysis. Nat. Cell Biol. 1960, 185, 416-422. [CrossRef] [PubMed]

22. Kendrew, J.C.; Bodo, G.; Dintzis, H.M.; Parrish, R.G.; Wyckoff, H.; Phillips, D.C. A Three-Dimensional Model of the Myoglobin Molecule Obtained by X-Ray Analysis. Nat. Cell Biol. 1958, 181, 662-666. [CrossRef] [PubMed]

23. Song, L.; Hobaugh, M.; Shustak, C.; Cheley, S.; Bayley, H.; Gouaux, J. Structure of Staphylococcal Alpha-Hemolysin, a Hep-tameric Transmembrane Pore. Science 1996, 274, 1859-1866. [CrossRef] [PubMed]

24. Petosa, C.; Collier, R.J.; Klimpel, K.R.; Leppla, S.H.; Liddington, R.C. Crystal Structure of the Anthrax Toxin Protective Antigen. Nat. Cell Biol. 1997, 385, 833-838. [CrossRef] [PubMed]

25. Goldie, K.N.; Abeyrathne, P.; Kebbel, F.; Chami, M.; Ringler, P.; Stahlberg, H. Cryo-Electron Microscopy of Membrane Proteins. Adv. Struct. Saf. Stud. 2014, 1117, 325-341. [CrossRef]

26. Murata, K.; Wolf, M. Cryo-Electron Microscopy for Structural Analysis of Dynamic Biological Nacromolecules. Biochim. Biophys. Acta Gen. Subj. 2018, 1862, 324-334. [CrossRef]

27. Ren, G.; Quispe, J.; Leppla, S.H.; Mitra, A.K. Large-Scale Structural Changes Accompany Binding of Lethal Factor to Anthrax Protective Antigen: A Cryo-Electron Microscopic Study. Structure 2004, 12, 2059-2066. [CrossRef]

28. Fabre, L.; Santelli, E.; Mountassif, D.; Donoghue, A.; Biswas, A.; Blunck, R.; Hanein, D.; Volkmann, N.; Liddington, R.; Rouiller, I. Structure of Anthrax Lethal Toxin Prepore Complex Suggests a Pathway for Efficient Cell Entry. J. Gen. Physiol. 2016, 148, 313-324. [CrossRef]

29. Gogol, E.; Engelman, D.; Zaccai, G. Neutron Diffraction Analysis of Cytochrome b5 Reconstituted in Deuterated Lipid Multilayers. Biophys. J. 1983, 43, 285-292. [CrossRef]

30. Torikai, N.; Yamada, N.L.; Noro, A.; Harada, M.; Kawaguchi, D.; Takano, A.; Matsushita, Y. Neutron Reflectometry on Interfacial Structures of the Thin Films of Polymer and Lipid. Polym. J. 2007, 39, 1238-1246. [CrossRef] 
31. McGillivray, D.; Valincius, G.; Heinrich, F.; Robertson, J.; Vanderah, D.J.; Febo-Ayala, W.; Ignatjev, I.; Lösche, M.; Kasianowicz, J.J. Structure of Functional Staphylococcus aureus Alpha-Hemolysin Channels in Tethered Bilayer Lipid Membranes. Biophys. J. 2009, 96, 1547-1553. [CrossRef] [PubMed]

32. Menestrina, G. Ionic Channels Formed by Staphylococcus aureus Alpha-Toxin: Voltage-Dependent Inhibition by Divalent and Trivalent Cations. J. Membr. Biol. 1986, 90, 177-190. [CrossRef]

33. Gouaux, J.E.; Braha, O.; Hobaugh, M.R.; Song, L.; Cheley, S.; Shustak, C.; Bayley, H. Subunit Stoichiometry of Staphylococcal Alpha-Hemolysin in Crystals and on Membranes: A Heptameric Transmembrane Pore. Proc. Natl. Acad. Sci. USA 1994, 91, 12828-12831. [CrossRef]

34. Kumar, S.; Tao, C.; Chien, M.; Hellner, B.; Balijepalli, A.; Robertson, J.; Li, Z.; Russo, J.J.; Reiner, J.; Kasianowicz, J.J.; et al. PEG-Labeled Nucleotides and Nanopore Detection for Single Molecule DNA Sequencing by Synthesis. Sci. Rep. 2012, 2, 684. [CrossRef]

35. Reiner, J.E.; Robertson, J.W.F.; Burden, D.L.; Burden, L.K.; Balijepalli, A.; Kasianowicz, J.J. Temperature Sculpting in Yoctoliter Volumes. J. Am. Chem. Soc. 2013, 135, 3087-3094. [CrossRef] [PubMed]

36. Reiner, J.; Balijepalli, A.; Robertson, J.; Drown, B.; Burden, D.L.; Kasianowicz, J.J. The Effects of Diffusion on an Exonuclease/Nanopore-Based DNA Sequencing Engine. J. Chem. Phys. 2012, 137, 214903. [CrossRef] [PubMed]

37. Fuller, C.; Kumar, S.; Porel, M.; Chien, M.; Bibillo, A.; Stranges, P.B.; Dorwart, M.; Tao, C.; Li, Z.; Guo, W.; et al. Real-Time Single-Molecule Electronic DNA Sequencing by Synthesis Using Polymer-Tagged Nucleotides on a Nanopore Array. Proc. Natl. Acad. Sci. USA 2016, 113, 5233-5238. [CrossRef] [PubMed]

38. Wang, H.; Kasianowicz, J.J.; Robertson, J.; Poster, D.L.; Ettedgui, J. A Comparison of Ion Channel Current Blockades Caused by Individual Poly(ethylene glycol) Molecules and Polyoxometalate Nanoclusters. Eur. Phys. J. E 2019, 42, 83. [CrossRef] [PubMed]

39. Ettedgui, J.; Kasianowicz, J.J.; Balijepalli, A. Single Molecule Discrimination of Heteropolytungstates and Their Isomers in Solution with a Nanometer-Scale Pore. J. Am. Chem. Soc. 2016, 138, 7228-7231. [CrossRef]

40. Robertson, J.W.F.; Rodrigues, C.G.; Stanford, V.M.; Rubinson, K.A.; Krasilnikov, O.V.; Kasianowicz, J.J. Single-Molecule Mass Spectrometry in Solution Using a Solitary Nanopore. Proc. Natl. Acad. Sci. USA 2007, 104, 8207-8211. [CrossRef]

41. Reiner, J.E.; Kasianowicz, J.J.; Nablo, B.J.; Robertson, J.W.F. Theory for Polymer Analysis Using Nanopore-Based Single-Molecule Mass Spectrometry. Proc. Natl. Acad. Sci. USA 2010, 107, 12080-12085. [CrossRef]

42. Reiner, J.E.; Balijepalli, A.; Robertson, J.W.F.; Campbell, J.; Suehle, J.; Kasianowicz, J.J. Disease Detection and Management via Single Nanopore-Based Sensors. Chem. Rev. 2012, 112, 6431-6451. [CrossRef]

43. Bezrukov, S.M.; Kasianowicz, J.J. Current Noise Reveals Protonation Kinetics and Number of Ionizable Sites in an Open Protein Ion Channel. Phys. Rev. Lett. 1993, 70, 2352-2355. [CrossRef] [PubMed]

44. Kasianowicz, J.J.; Bezrukov, S.M. Protonation Dynamics of the Alpha-Toxin Ion Channel from Spectral Analysis of PH-Dependent Current Fluctuations. Biophys. J. 1995, 69, 94-105. [CrossRef]

45. Cornell, B.A.; Braach-Maksvytis, V.L.B.; King, L.G.; Osman, P.D.J.; Raguse, B.; Wieczorek, L.; Pace, R.J. A Biosensor that Uses Ion-Channel Switches. Nat. Cell Biol. 1997, 387, 580-583. [CrossRef] [PubMed]

46. Knoll, W. Interfaces and Thin Films as Seen by Bound Electromagnetic Waves. Annu. Rev. Phys. Chem. 1998, 49, 569-638. [CrossRef]

47. Valincius, G.; Mickevicius, M. Chapter Two-Tethered Phospholipid Bilayer Membranes: An Interpretation of the Electrochemical Impedance Response. In Advances in Planar Lipid Bilayers and Liposomes; Iglič, A., Kulkarni, C.V., Rappolt, M.B.T.-A., Eds.; Academic Press: New York, NY, USA, 2015; Volume 21, pp. 27-61. [CrossRef]

48. Jiang, J.; Pentelute, B.L.; Collier, R.J.; Zhou, Z.H. Atomic Structure of Anthrax Protective Antigen Pore Elucidates Toxin Translocation. Nat. Cell Biol. 2015, 521, 545-549. [CrossRef]

49. Benson, E.L.; Huynh, P.D.; Finkelstein, A.A.; Collier, R.J. Identification of Residues Lining the Anthrax Protective Antigen Channel. Biochemistry 1998, 37, 3941-3948. [CrossRef]

50. Akabas, M.H.; Stauffer, D.A.; Xu, M.; Karlin, A. Acetylcholine Receptor Channel Structure Probed in Cysteine-Substitution Mutants. Science 1992, 258, 307-310. [CrossRef]

51. Zaccai, G.; Jacrot, B. Small Angle Neutron Scattering. Annu. Rev. Biophys. Bioeng. 1983, 12, 139-158. [CrossRef]

52. Jacrot, B. The Study of Biological Structures by Neutron Scattering from Solution. Rep. Prog. Phys. 1976, 39, 911-953. [CrossRef]

53. Schoenborn, B.P. Neutrons in Biology; Springer: New York, NY, USA, 1984.

54. Svergun, D.; Koch, M.H.J. Small-Angle Scattering Studies of Biological Macromolecules in Solution. Rep. Prog. Phys. 2003, 66, 1735-1782. [CrossRef]

55. Ostanevich, Y.M.; Serdyuk, I.N. Neutron-Diffraction Studies of the Structure of Biological Macromolecules. Sov. Phys. Uspekhi 1982, 25, 323-339. [CrossRef]

56. Feld, G.K.; Kintzer, A.F.; I Tang, I.; Thoren, K.L.; Krantz, B.A. Domain Flexibility Modulates the Heterogeneous Assembly Mechanism of Anthrax Toxin Protective Antigen. J. Mol. Biol. 2012, 415, 159-174. [CrossRef] [PubMed]

57. Fischer, H.; Polikarpov, I.; Craievich, A.F. Average Protein Density is a Molecular-Weight-Dependent Function. Protein Sci. 2009, 13, 2825-2828. [CrossRef] [PubMed]

58. Bauer, B.J.; Hobbie, A.E.K.; Becker, M.L. Small-Angle Neutron Scattering from Labeled Single-Wall Carbon Nanotubes. Macromolecules 2006, 39, 2637-2642. [CrossRef] 
59. Schaefer, D.W.; Martin, J.E.; Wiltzius, P.; Cannell, D.S. Fractal Geometry of Colloidal Aggregates. Phys. Rev. Lett. 1984, 52, 2371-2374. [CrossRef]

60. Thoren, K.L.; Krantz, B.A. The Unfolding Story of Anthrax Toxin Translocation. Mol. Microbiol. 2011, 80, 588-595. [CrossRef]

61. Fischer, A.; Holden, M.A.; Pentelute, B.L.; Collier, R.J. Ultrasensitive Detection of Protein Translocated Through Toxin Pores in Droplet-Interface Bilayers. Proc. Natl. Acad. Sci. USA 2011, 108, 16577-16581. [CrossRef] [PubMed]

62. Kintzer, A.F.; Sterling, H.J.; Tang, I.I.; Williams, E.R.; Krantz, B.A. Anthrax Toxin Receptor Drives Protective Antigen Oligomerization and Stabilizes the Heptameric and Octameric Oligomer by a Similar Mechanism. PLoS ONE 2010, 5, e13888. [CrossRef]

63. Feld, G.K.; Thoren, K.L.; Kintzer, A.F.; Sterling, H.J.; I Tang, I.; Greenberg, S.G.; Williams, E.R.; A Krantz, B. Structural Basis for the Unfolding of Anthrax Lethal Factor by Protective Antigen Oligomers. Nat. Struct. Mol. Biol. 2010, 17, 1383-1390. [CrossRef]

64. Mogridge, J.; Cunningham, A.K.; Collier, R.J. Stoichiometry of Anthrax Toxin Complexes. Biochemistry 2002, 41, 1079-1082. [CrossRef]

65. Blaustein, R.O.; Koehler, T.M.; Collier, R.J.; Finkelstein, A. Anthrax Toxin: Channel-Forming Activity of Protective Antigen in Planar Phospholipid Bilayers. Proc. Natl. Acad. Sci. USA 1989, 86, 2209-2213. [CrossRef]

66. Langmuir, I. The Adsorption of Gases on Plane Surfaces of Glass, Mica and Platinum. J. Am. Chem. Soc. 1918, 40, 1361-1403. [CrossRef]

67. Andreoli, T.E.; Troutman, S.L. An Analysis of Unstirred Layers in Series with "Tight" and "Porous" Lipid Bilayer Membranes. J. Gen. Physiol. 1971, 57, 464-478. [CrossRef]

68. Gutknecht, J.; Tosteson, D.C. Diffusion of Weak Acids across Lipid Bilayer Membranes: Effects of Chemical Reactions in the Unstirred Layers. Science 1973, 182, 1258-1261. [CrossRef]

69. McLaughlin, S.G.; Dilger, J. Transport of Protons Across Membranes by Weak Acids. Physiol. Rev. 1980, 60, 825-863. [CrossRef]

70. Pohl, P.; Saparov, S.M.; Antonenko, Y.N. The Size of the Unstirred Layer as a Function of the Solute Diffusion Coefficient. Biophys. J. 1998, 75, 1403-1409. [CrossRef]

71. Pedley, T.J. Calculation of Unstirred Layer Thickness in Membrane Transport Experiments: A Survey. Q. Rev. Biophys. 1983, 16, 115-150. [CrossRef] [PubMed]

72. Montal, M.; Mueller, P. Formation of Bimolecular Membranes from Lipid Monolayers and a Study of Their Electrical Properties. Proc. Natl. Acad. Sci. USA 1972, 69, 3561-3566. [CrossRef]

73. Glinka, C.J.; Barker, J.G.; Hammouda, B.; Krueger, S.; Moyer, J.J.; Orts, W.J. The $30 \mathrm{~m}$ Small-Angle Neutron Scattering In-struments at the National Institute of Standards and Technology. J. Appl. Cryst. 1998, 31, 430-445. [CrossRef]

74. Rubinson, K.A. Practical Corrections for $\mathrm{p}(\mathrm{H}, \mathrm{D})$ Measurements in Mixed $\mathrm{H}_{2} \mathrm{O} / \mathrm{D}_{2} \mathrm{O}$ Biological Buffers. Anal. Methods 2017, 9 , 2744-2750. [CrossRef]

75. Kline, S.R. Reduction and Analysis of SANS and USANS Data Using IGOR Pro. J. Appl. Crystallogr. 2006, 39, 895-900. [CrossRef] 